OPEN ACCESS

Edited by:

Javier Ochoa-Reparaz, Eastern Washington University,

United States

Reviewed by:

Linda Saif,

The Ohio State University,

United States

Jiri Mestecky,

University of Alabama at Birmingham,

United States

*Correspondence:

Eliana Mariño

eliana.marino@monash.edu

Specialty section:

This article was submitted to

Mucosal Immunity,

a section of the journal

Frontiers in Immunology

Received: 02 August 2018

Accepted: 24 October 2018

Published: 20 November 2018

Citation:

Yap YA and Mariño E (2018) An Insight Into the Intestinal Web of Mucosal Immunity, Microbiota, and Diet in Inflammation. Front. Immunol. 9:2617.

doi: 10.3389/fimmu.2018.02617

\section{An Insight Into the Intestinal Web of Mucosal Immunity, Microbiota, and Diet in Inflammation}

\author{
Yu Anne Yap and Eliana Mariño* \\ Faculty of Medicine, Nursing and Health Sciences, School of Biomedical Sciences, Monash University, Clayton, VIC, Australia
}

The rising global incidence of autoimmune and inflammatory conditions can be attributed to changes in the large portion of the immune system that belongs to our gastrointestinal tract (Gl). The intestinal immune system serves as a gatekeeper to prevent pathogenic invasions and to preserve a healthier gut microbiota. The gut microbiota has been increasingly studied as a fundamental contributor to the state of health and disease. From food fermentation, the gut microbiota releases metabolites or short chain fatty acids (SCFAs), which have anti-inflammatory properties and preserve gut homeostasis. Immune responses against food and microbial antigens can cause inflammatory disorders such as inflammatory bowel disease (IBD) and celiac disease. As such, many autoimmune and inflammatory diseases also have a "gut origin". A large body of evidence in recent years by ourselves and others has uncovered the link between the immune system and the SCFAs in specific diseases such as autoimmune type 1 diabetes (T1D), obesity and type 2 diabetes (T2D), cardiovascular disease, infections, allergies, asthma, and IBD. Thus, the power of these three gut dynamic components - the mucosal immunity, the microbiota, and diet-can be harnessed in tandem for the prevention and treatment of many inflammatory and infectious diseases.

Keywords: mucosal immunity, gut microbiota, SCFAs, diet, IELs, autoimmunity, diabetes, infections

\section{INTRODUCTION}

Considered the largest immunological organ in our body, the gut is in constant contact with food antigens, commensal microbiota, and foreign pathogens. As such, the gut has evolved extremely dynamic anatomy capable of regulating innate and adaptive immune responses to manage these interfaces effectively (1). In a homeostatic environment, there is a mutualistic relationship between the host and the microbiota. Keeping the delicate balance between mucosal immunity and microbiota (commensal bacteria) is a complex process. A disruption to the gut microbiota ecology, also known as dysbiosis, can lead or contribute to disease (2-4). While the host provides a nutrientrich environment, the microbiota, in turn, provides the host with an increased capacity to harvest nutrients from food and boost the host immune system. The mucosal immune system, as a physical barrier, prevents pathogenic microorganisms and immunogenic components from traversing from the mucosae into the internal environment of the host. At the same time, this tightly regulated system has the important task of inducing tolerance to antigens (1). Here, we review the complex interplay between intestinal immunity, gut microbiota, and diet in inflammatory diseases (Table 1), such as T1D and IBD (22), and infection in humans and animal models. 
TABLE 1 | Diet, intestinal immunity and microbiota in diseases.

\begin{tabular}{|c|c|c|c|}
\hline \multirow[t]{2}{*}{ Disease } & \multirow{2}{*}{$\begin{array}{l}\text { Involvement of intestinal immunity and the gut } \\
\text { microbiota }\end{array}$} & \multicolumn{2}{|c|}{ References } \\
\hline & & Animal models & Humans \\
\hline \multirow[t]{3}{*}{ Type 1 diabetes (T1D) } & - Limited or altered microbiota diversity & $(5-12)$ & $(13-21)$ \\
\hline & - Increased gut permeability & & \\
\hline & $\begin{array}{l}\text { - Intestinal immune system in a constant state of } \\
\text { pro-inflammation }\end{array}$ & & \\
\hline \multirow[t]{3}{*}{$\begin{array}{l}\text { Inflammatory bowel } \\
\text { disease (IBD) }\end{array}$} & $\begin{array}{l}\text { - Reduction of butyrate-producing } \\
\text { bacteria/butyrate production }\end{array}$ & $(22,23)$ & $(24,25)$ \\
\hline & $\begin{array}{l}\text { - Tryptophan-rich diet and L.reuteri induced } \\
\text { differentiation of TCR } \alpha \beta^{+} \mathrm{CD} 4^{+} \mathrm{CD} 8 \alpha \alpha^{+} \text {IELs } \\
\text { associated with protection }\end{array}$ & $(26-29)$ & \\
\hline & - Pathogenic role for TCR $\gamma \delta^{+}$IELs in colitis & $(30,31)$ & \\
\hline \multirow[t]{2}{*}{ Infections } & $\begin{array}{l}\text { - Absence of commensal microbiota regulated } \\
\text { CD } 8 \alpha \beta^{+} \text {IELs associated with protection against } \\
\text { bacterial and viral infections }\end{array}$ & $(32-35)$ & \\
\hline & $\begin{array}{l}\text { - Crosstalk between IECs and TCR } \gamma \delta^{+} \text {IELs within } \\
\text { the epithelium prevented pathogen invasion }\end{array}$ & $(36-40)$ & \\
\hline
\end{tabular}

\section{DYNAMIC TRIO: INTESTINAL IMMUNE SYSTEM, GUT MICROBIOTA, AND DIET}

A network of intestinal immune cells resides within the epithelium and consists of three distinct lymphoid structures. This physical and biochemical barrier to commensal and pathogenic microorganisms is formed by the epithelium layer, the lamina propria layer (LPL) and the gut-associated lymphoid tissues (GALT). The GALT comprises the mesenteric lymph nodes (MLNs), the Peyer's patches (PPs) and isolated lymphoid follicles (ILFs) (1). Intestinal epithelial cells (IECs) have fundamental immuno-regulatory functions. For example, trans-presentation of IL-15 by IECs drives the development and differentiation of immuno-regulatory $\mathrm{CD} 8 \alpha \alpha$ intraepithelial lymphocytes (IELs) (41). Furthermore, overexpression of epithelial IL-15 is essential for the motility and localization of protective $\gamma \delta$ IELs into the epithelium of small intestine (42). The IECs also express anti-inflammatory cytokines such as IL-10, which likely contributes to tolerance to commensal bacteria and epithelial integrity through epithelial-macrophage crosstalk (43). Besides that, epithelial cells are reinforced by tight junctions to form an interconnected network that acts as the main mechanical barrier of the intestinal mucosal surface. Tight junctions, such as zonulins, occludins and claudins, are essential for border control and are strictly regulated in response to various signals to preserve cellular polarity (44). Specialized IECs such as goblet and Paneth cells reinforce barrier function by the secretion of antimicrobial peptides (AMPs) by enterocytes (45). These AMPs, such as C-type lectin regenerating islet-derived protein III $\gamma$ (REGIII $\gamma$ ) and defensins, disrupt surface membranes of bacteria; thus enabling a broad regulation of commensal and pathogenic bacteria (46-48).

The intestinal innate immune system mediates the symbiotic relationship between the host and the gut microbiota. Myeloid differentiation primary response gene 88 (MyD88) is a central adaptor molecule for the majority of Toll-like receptors (TLRs) involved in pathogen recognition. To preserve symbiosis, IECs need to recognize pathogenic molecule patterns. Previous data support MyD88 playing a key role in regulating the immune system by shaping the gut microbiota (6). Furthermore, IEC MyD88 has been suggested to act as a primary sensor involved in the cross-talk between nutrients, the gut microbiota and the host during diet-induced obesity (DIO) (49). The specific deletion of IEC MyD88 partially protected against DIO, diabetes and inflammation. Previously, Ley et al. (50) discovered that genetically obese mice have a $50 \%$ reduction in the abundance of Bacteroidetes and a proportional increase in Firmicutes. In another study, the authors performed microbiota transplantation experiments and demonstrated that the obese microbiota had an increased capacity to harvest energy from the diet (51). Additionally, IECs are also involved in the adaptive immune regulation of gut homeostasis mediated by IgA (52). Another type of specialized IECs is concentrated in the follicle-associated epithelium which overlays the luminal surface of lymphoid structures including PPs and ILFs. These microfold cells or $\mathrm{M}$ cells facilitate the sampling of luminal antigens and intact microorganisms for presentation to the intestinal immune system $(53,54)$. While both $\mathrm{M}$ cells and goblet cells have been shown to be involved in antigen delivery to the LPL, their functional importance to and influence on the regulation of pathogen responses or immune tolerance remain incompletely identified.

The connections between the gut microbiota and the mucosal immunity are vastly influenced by dietary fiber and microbial SCFAs. Fermentation of different foods, such as indigestible polysaccharides by the gut micrbiota, produces SCFA acetate, propionate and butyrate $(55,56)$. For instance, Bacteroides thetaiotaomicron, an acetate producer, upregulated KLF4, which is involved in goblet cell differentiation and increased expression of mucin-related genes. Faecalibacterium prausnitzii, an acetate consumer and butyrate producer, attenuated the effects of $B$. 
thetaiotaomicron to prevent mucus overproduction, necessary for a healthier epithelium structure and composition (57). The gut epithelium is covered by a mucus layer and its integrity is vital to prevent microbe invasions and infections (1). As elucidated by Desai et al. (58), a chronic or intermittent dietary fiber deficiency caused the gut microbiota to resort to using hostsecreted mucus glycoproteins as a nutrient source, leading to erosion of the colonic mucus barrier. The goblet cells secrete heavily glycosylated proteins called mucins into the intestinal lumen as a first line of defense against microbial invasion (45). Mucin 2 (MUC2), the most abundant of these mucins, is pivotal in shaping the intestinal mucus layers at epithelial surfaces. Mice deficient in MUC2 experienced fatal colitis when infected with Citrobacter rodentium (59). It is striking to observe that simple deprivation of dietary fiber in wild-type mice for either the whole duration or intermittently in the 40-day study period was sufficient to imitate the phenotype in MUC2-deficient mice. Furthermore, a prolonged lack of dietary fiber is associated with increased abundance of mucin-degrading bacteria such as Akkermansia muciniphila (58). Consistent with this, feeding mice a Western diet with very low fiber content has been shown to strongly affect gut microbiota composition, reduce mucus growth rate and increase penetrability of the inner colonic mucus layer (60). Given that fiber is the primary source of energy for the gut microbiota, the results ascribed to the above studies point to the critical effect of microbial SCFAs. As such, Bifidobacterium strains have long been used as probiotics, with several beneficial effects attributed in part to the increased production of acetate (61). For example, colonization of germ-free (GF) mice with bifidobacteria prevented translocation of enteropathogenic Escherichia coli O157 (61). Although supplementation of $1 \%$ inulin (a prebiotic with bifidogenic effect) or Bifidobacterium longum prevented mucus defects, it was insufficient to improve metabolic parameters of obese animals. Contrastingly, a high intake of $20 \%$ inulin reduced microbiota encroachment into the mucosa, prevented colonic atrophy and increased intestinal epithelial proliferation, thereby protecting mice against DIO (62).

\section{IELS: FRIEND OR FOE IN DISEASE?}

To sustain gut barrier integrity, the mucosal immune system is prepared to provide extra protection against infection and inflammation. Commonly referred to as intestinal intraepithelial lymphocytes (IELs) (63), most IELs express the CD8 $\alpha \alpha$ homodimer and approximately $90 \%$ express $\mathrm{T}$ cell receptors (TCRs) (64) and can be classified as induced (conventional) or natural (unconventional). Induced IELs are derived from peripheral $\mathrm{T}$ cells that home to the intestinal epithelium after encountering antigens in gut-associated lymphoid tissues (GALT). Induced IELs can be divided into subsets that express either $\mathrm{CD} 4$ or $\mathrm{CD} 8 \alpha \beta$, upon entering the intestinal epithelium (63). Induced IELs typically exhibit an effectormemory-like phenotype and are thought to have a protective role against pathogenic invasions (63). A fraction of the induced TCR $\alpha \beta^{+} \mathrm{CD}^{+} \mathrm{T}$ cells migrate to the intestinal epithelium upon activation in GALT where they can act as effector or tissue-resident memory $\mathrm{T}$ cells. While $\mathrm{CD} 4^{+} \mathrm{T}$ cells have been traditionally thought to lose the CD8 chains after thymic development, some studies have reported the existence of TCR $\alpha \beta^{+} \mathrm{CD}^{+}$IELs that also express CD $8 \alpha \alpha$ both in mice (65, 66) and humans (67), which do not possess every quality of mature $\mathrm{CD}^{+} \mathrm{T}$ cells. In order to gain expression of CD $8 \alpha \alpha$, mature $\mathrm{CD}^{+} \mathrm{T}$ cells need to reactivate CD8-lineage genes by terminating expression of $\mathrm{T}$ helper master regulator (ThPOK), while concurrently upregulating expression of the transcription factors Runx3 (68) and T-bet (69). External stimuli within the intestinal epithelium, for example, TGF- $\beta$, retinoic acid, IFN- $\gamma$, and IL-27, serve as cues for the re-differentiation of CD4 ${ }^{+} \mathrm{T}$ cells (69-71).

Recent data confirm the gut microbiota as yet another central factor in the generation of TCR $\alpha \beta^{+} \mathrm{CD} 4{ }^{+} \mathrm{CD} 8 \alpha \alpha^{+}$IELs (26). For example, a tryptophan metabolizing commensal microorganism called Lactobacillus reuteri has been revealed to activate the transcription factor aryl hydrocarbon receptor (AhR), important for immune regulation in mucosal inflammation. Tryptophan is mostly found in foods such as oats, dairy products, seeds and, nuts. Mice without $L$. reuteri have significantly low numbers of $\mathrm{TCR} \alpha \beta^{+} \mathrm{CD} 4{ }^{+} \mathrm{CD} 8 \alpha \alpha^{+}$IELs, and reconstitution of $L$. reuteri in these mice, coupled with a diet rich in tryptophan, was adequate to induce $\mathrm{TCR} \alpha \beta^{+} \mathrm{CD} 4{ }^{+} \mathrm{CD} 8 \alpha \alpha^{+}$IELs differentiation (26). This IEL subset has an immune regulatory effect in the prevention of $\operatorname{IBD}(27,28)$. An elegant study by Sujino and colleagues further demonstrated a microbiota-dependent conversion of LPL Foxp $3^{+} \mathrm{T}_{\text {regs }}$ into $\mathrm{TCR} \alpha \beta^{+} \mathrm{CD} 4^{+} \mathrm{CD} 8 \alpha \alpha^{+}$ IELs upon migration to the epithelium to control intestinal inflammation (29). TCR $\alpha \beta^{+} \mathrm{CD} 8 \alpha \beta^{+}$IELs are another type of induced IELs that make up $10-15 \%$ of the IEL population in mice (63) and $70-80 \%$ in humans (67). The majority of this subset is derived from peripherally activated $\mathrm{CD} 8^{+} \mathrm{T}$ cells that eventually migrate to the intestinal epithelium (72) and remain there. These cells have properties distinct to antigen-experienced $\mathrm{CD}^{+} \mathrm{T}$ cells found in peripheral lymphoid organs (73) in the expression of activation markers and cytokine secretion. The expression of CD8 $\alpha \alpha$, which decreases the sensitivity of the TCR to antigens, is another main factor differentiating peripheral and intestinal $\mathrm{CD}^{+} \mathrm{T}$ cells (74). Presently, the role of TCR $\alpha \beta^{+} \mathrm{CD} 8 \alpha \beta^{+}$IELs in mucosal immunity is still unclear. Adoptive transfer studies have demonstrated a protective function of antigen-specific $\operatorname{CD} 8 \alpha \beta^{+}$ IELs in mouse models of bacterial and viral infections $(32,33)$. Although the CD $8 \alpha \beta^{+}$IELs are strongly cytotoxic, they typically encounter commensal bacteria rather than invasive pathogenic microorganisms. Many studies comparing conventional, GF and antibiotic-treated mice and attempting to explore the connection between commensal bacteria and CD8 $\alpha \beta^{+}$IELs have found a positive relationship, where the former may be involved in regulating the number of $\operatorname{CD} 8 \alpha \beta^{+}$IELs in the intestinal epithelium $(34,35)$. Whilst that may be true, the mechanism behind this phenomenon is unknown. A recent study by Chen et al. (75) identified a series of genes that encode antimicrobial peptides, especially $\alpha$-defensins, in commensal-dependent CD $8 \alpha \beta^{+}$IELs using microarray analysis. Applying 16S rDNA sequencing techniques in their microbiotatransplantation experiment, the authors showed that depleting 
the Bifidobacterium species using antibiotics increased the number of CD $8 \alpha \beta^{+}$IELs. They further demonstrated that the IL15/IL-15R complex influenced by commensal bacteria enhanced the antimicrobial activity of $\mathrm{CD} 8 \alpha \beta^{+}$IELs in vitro. However, the mechanistic link showing how a specific bacterial species or particular microbial metabolites could influence these IEL subsets remains unexplored.

While the gut immune system can replenish itself, interaction with the thymus is also essential to support gut homeostasis. Natural IELs such as TCR $\gamma \delta^{+}$cells migrate directly to the intestinal epithelium after development in the thymus (63). However, there is evidence to suggest the extrathymic origin of many $\mathrm{TCR} \gamma \delta^{+}$IELs (76). TCR $\gamma \delta^{+}$cells are not only limited to the intestines, but have also been found in other mucosal sites such as the skin and uterus where they contribute to the maintenance of barrier integrity (77). These cells have been shown to have dynamic migratory patterns within the intestinal epithelium mediated by occludin, a tight junction protein (36, 37). We found that increased expression of occludin in the colon of non-obese diabetic (NOD) mice fed with a high butyrateyielding diet was associated with protection against autoimmune diabetes (5). Remarkably, we found butyrate increased colonic TCR $\gamma \delta^{+}$IELs correlated to increased expression of IL-15 in the thymus (Y. Yap, J. L. Richards \& E. Mariño, unpublished data). Epithelial IL-15 is essential for the migration of TCR $\gamma \delta^{+}$ IELs into the intestinal epithelium (42). Additional in vitro analyses further supported the importance of epithelial IL-15 and IL-2R $\beta$ in TCR $\gamma \delta^{+}$IEL motility within the intestinal mucosa. Impaired IL-2R $\beta$ signaling and overproduction of IL-15 locally in the lamina propria resulted in acute pathogenic Salmonella typhimurium invasion and enhanced bacterial translocation (42). A fundamental role of TCR $\gamma \delta^{+}$IELs is to protect the intestinal epithelium against pathogenic microorganisms and inflammation. Crucial in the mucosal immune response against resident intestinal bacteria, TCR $\gamma \delta^{+}$IELs produce antimicrobial effectors such as RegIII $\gamma$ when in contact with resident bacterial pathobiont within the IECs (38). This antibacterial response is dependent on MyD88 signaling in IECs, which further highlights the microbe-dependent cues for TCR $\gamma \delta^{+}$IEL homeostasis. This crosstalk between IECs and TCR $\gamma \delta^{+}$IELs is not only crucial for intestinal homeostasis with resident microbiota but also necessary in the protection against pathogens, such as S. typhimurium (38), Toxoplasma gondii (39) or the parasitic Nippostrongylus brasiliensis (40). The function of TCR $\gamma \delta^{+}$IELs may differ between the small intestine and colon and may be regulated by different mechanisms depending on the presence of injury to mucosal tissues $(38,78,79)$. To protect the epithelium against inflammatory damage during infection, TCR $\gamma \delta^{+}$IELs produce a variety of factors such as TGF- $\beta$ and keratinocyte growth factor (KGF) to promote healing and integrity of the intestinal epithelium (80).

The cytotoxic and repairing properties of TCR $\gamma \delta^{+}$IELs is evident in infections by fighting off early microbial invasion and limiting excessive tissue damage at the end of the infection phase. In experimental models of colitis, TCR $\gamma \delta^{+}$IELs appear to have diverging roles. Some studies have demonstrated a pathogenic role for these cells in colitis induction $(30,31)$. Interestingly, as the disease progressed to its later stages, TCR $\gamma \delta^{+}$IELs play a protective role against inflammation-induced epithelium damage (81, 82). Mice lacking cytosolic sensor for microbial DNA, STING, are highly susceptible to colitis and acute infection (83). Exacerbated colonic inflammation correlated with a significantly higher frequency of natural TCR $\gamma \delta^{+}$IELs, decreased induced TCR $\alpha \beta^{+} \mathrm{CD} 8 \alpha \beta^{+}$and TCR $\alpha \beta^{+} \mathrm{CD} 8 \alpha \alpha^{+}$IELs and impaired development and function of Foxp $3^{+} \mathrm{T}_{\text {regs. }}$. As such, these findings strongly suggest the highly variable impact of the microbiota on the frequency and function of intestinal IELs in infection settings. Intestinal IELs have largely been studied in disease settings where they are involved in mechanistic links with the gut microbiota. In fact, mice were protected from ischemic stroke when intestinal homeostasis was restored (84). Mice induced with acute brain injury presented an altered gut microbiota, which promote the trafficking of effector IL17-producing $\mathrm{TCR} \gamma \delta^{+}$cells from the small intestine to brain. Protection against ischemic stroke was correlated with the suppression of effector TCR $\gamma \delta^{+}$cells (84). In autoimmune diabetes, TCR $\gamma \delta^{+}$cells, depending on their origin and condition, can either protect (85-87) or exacerbate (7) the disease, once again highlighting the dual role of these cells in disease.

\section{DIETARY FACTORS IN ACTION}

Environmental factors are dominant over host genetics in shaping the human gut microbiota (88). As we have shown, diet is one environmental factor that highly influences the gut microbiota and the immune system $(5,22,89,90)$. Diet is composed of different macro- and micronutrients, and natural sources of fiber are necessary for the production of SCFAs (56). Conversely, changes in our dietary habits to include highly processed and refined foods, additives such as emulsifiers and preservatives, can negatively impact on gut microbial composition, which may adversely affect our health (91-94). Acetate, propionate and butyrate contribute to a healthy gut microbiota and for a mature and developed immune system (55). We have shown in a mouse model of colitis, the SCFAs, acetate and butyrate protected against intestinal epithelial damage in DSS-induced colitis (22). High fiber feeding promoted the release of SCFAs, which led to inflammasome activation through GPR43 and GPR109A (22). This event led to the production and secretion of IL-18, a cytokine involved in repairing intestinal epithelial integrity, and homeostasis. The high levels of IL18 and protection from DSS colitis were associated with a significant increase in Bacteroidetes, which were predominantly found in mice fed a high fiber diet. Conversely, species that were considerably low or absent in mice fed a zero-fiber diet were bacteria from the genus Prevotella, known to contain a set of bacterial genes for cellulose and xylan hydrolysis. This is consistent with findings in children from rural Burkina Faso study, whose microbial diversity is associated with the extraction of valuable nutrition from fibrous plant foods $(95,96)$.

SCFAs also regulate the immune cells that reside in the LPL. As such tolerogenic mucosal CD103 ${ }^{+}$dendritic cells (DC) conferred protection in a murine food allergy model through high fiber 
feeding. In this study, we found a high fiber diet increased the release of acetate and butyrate associated with enhanced oral tolerance and retinal dehydrogenase (RALDH) activity (90). Furthermore, protection from food allergy was dependent on vitamin A found in the diet. Accordingly, mice lacking GPR43 or GPR109A (metabolite sensing receptors for acetate and butyrate) displayed exacerbated food allergy and reduced CD103 ${ }^{+}$DCs. Likewise, butyrate produced by commensal bacteria promotes peripheral $\mathrm{T}_{\text {reg }}$ generation via inhibition of histone deacetylases (HDAC) inhibition (97) or the induction of tolerogenic DCs (90) in mice. Similarly, in vitro studies show butyrate to be a potent inducer of human tolerogenic DCs by inducing RALDH activity and type 1 regulatory $\mathrm{T}$ cells ( $\operatorname{Tr} 1)$ differentiation via simultaneous HDAC inhibition and signaling through GPR109A (98). Previous gut microbiome analysis revealed a significant reduction in the number of butyrate-producing bacteria, such as Firmicutes and Lachnospiraceae in the colon of patients with IBD (24) and colorectal cancer (25). The gut microbiota through GPR109A signaling have anti-inflammatory properties by promoting colonic macrophages and DCs to induce differentiation of $\mathrm{T}_{\text {reg }}$ cells and immune-regulatory IL10-producing T cells (23). GPR109A was also essential to induce IL-18 via a butyrate-mediated pathway in the colonic epithelium for intestinal integrity. Besides butyrate, GPR109A also acts as a receptor for niacin (or vitamin B3), which is also produced by the gut microbiota. Accordingly, niacin-deficient $\left(\mathrm{Niacr}^{-/-}\right)$ mice displayed exacerbated DSS-induced colitis pathogenesis. Complete ablation of the gut microbiota or depletion of dietary fiber greatly increased the risk for DSS-induced colitis and colon cancer in mice (23). As previously discussed, there is a duality in the role of IELs in infection. We and others have found that a high acetate-yielding diet reduced colonic atrophy and inflammation in mice affected with $C$. rodentium infection in a GPR43dependent manner (99) (K. H. McLeod, Y. Yap \& E. Mariño, paper under review). SCFAs mediated by GPCRs conditioned the IECs to produce inflammatory cytokines and chemokines such as IL-6, CXCL1 and CXCL10 for a timely response against bacterial products in the protection against infection; thus highlighting again the critical connections between intestinal immunity, the gut microbiota and diet (99).

As previously mentioned, the SCFAs can exert their antiinflammatory properties through HDAC inhibition (97, 100, 101). We have shown that feeding mice a high fiber diet enhanced $\mathrm{T}_{\text {reg }}$ numbers and function, which protected them against allergic airways disease (AAD) (89). In that study, we demonstrate that dietary acetate inhibited HDAC9 by increasing acetylation at the Foxp3 promoter, which led to increased $\mathrm{T}_{\text {reg }}$ cells (89). Further analyses demonstrated an increase in fecal and serum SCFA concentrations, particularly acetate, and identified the dominance of an acetate-producing bacteria, Bacteroides acidifaciens A40(T) strain in mice fed a high fiber diet. Likewise, another study reported that dietary fiber and the SCFA propionate protected against AAD in mice (102) in a GPR41-dependent manner. Dietary fiber decreased the ratio of Firmicutes to Bacteroidetes. Furthermore, mice treated with propionate had alterations in bone marrow hematopoiesis marked by enhanced generation of macrophage and dendritic cell (DC) precursors with impaired Th2 response in the lung. We observed in both mice and humans that a higher intake of dietary fiber during pregnancy was associated with a higher concentration of serum acetate and increased protection against the development of airway disease in offspring (89).

\section{PUTTING THE BRAKES ON AUTOIMMUNE T1D}

T1D is one of the most common autoimmune diseases that results in specific $\mathrm{T}$ cell-mediated destruction of pancreatic $\beta$-cells in genetically susceptible individuals (103). Although most of the action occurs in the pancreas and adjacent lymph nodes, the gut has been implicated as an early regulator of disease progression $(104,105)$. In fact, the progressive rise in global T1D incidence $(106,107)$ points to environmental factors, such as infections, antibiotics and diet, having a great impact on the development of T1D $(94,108-110)$. We believe that studying the synergistic roles of the intestinal barrier, the microbiota composition and the mucosal immune system offer potential intervention targets to treat T1D. Evidence shows that NOD mice $(5,8-10)$ and children diagnosed with T1D have a distinct and limited gut microbiota diversity (13), with an increased ratio of Bacteroidetes to Firmicutes, compared to healthy individuals (14). Furthermore, metagenomic data showed a significant reduction in abundance of butyrate producers, such as Faecalibacterium, and mucin degraders, such as Prevotella and Akkermansia (15, 16). This is in contrast with other SCFA producers such as Bacteroides and Alistipes, which were more abundant in the feces of diabetic individuals (15). As mentioned previously, butyrate is central for epithelial integrity, therefore an altered gut microbiota composition may contribute to a "leaky" gut and aberrant intestinal immune system, all contributing to the etiology of T1D.

In $\mathrm{T} 1 \mathrm{D}$, increased gut permeability contributes to intestinal inflammation, shown in both animal models (11) and human patients (17). Likewise, intestinal infection that promote a "leaky" gut also promoted accelerated T1D in mice by increased activation and proliferation of diabetogenic $\mathrm{CD}^{+} \mathrm{T}$ cells in the pancreatic lymph nodes (PLNs) (111). The role of the gut in the loss of tolerance to self-antigens that leads to autoimmune T1D is poorly understood. However, an unbalanced host-microbe interaction and excess of food and microbial antigens may skew the intestinal immune system toward a perpetually pro-inflammatory state (12). Likewise, children with T1D show overall increased intestinal immune activation by high IL-4, IL- $1 \alpha$ and IFN- $\gamma$ protein expression in the small intestine LPL (18). The number of regulatory Foxp $3^{+} \mathrm{T}_{\text {regs }}$ are reduced and/or inactive in biopsied small intestine tissues in T1D patients (19). Moreover, it has been reported that children newly diagnosed with $\mathrm{T} 1 \mathrm{D}$ had reduced Foxp $3^{+} \mathrm{T}_{\text {regs }}$ and increased IL-17-expressing $\mathrm{CD} 4^{+}$and $\mathrm{CD} 8^{+} \mathrm{T}$ cells in the blood, indicating the absence of immune suppression mechanisms (20). In contrast, adoptive transfer of splenic IL-17-producing TCR $\gamma \delta^{+}$cells did not exacerbate diabetes in NOD mice, but instead had regulatory effects through TGF- $\beta$ upregulation (87). 
Inducing mucosal immune tolerance through aerosolized insulin has been considered a therapeutic approach to treat T1D in secondary prevention studies. Interestingly, transfer of purified splenic $\mathrm{CD}^{+} \gamma \delta \mathrm{T}$ cells from diabetic NOD mice treated with insulin aerosol suppressed diabetes. Protection was associated with reduced insulin ${ }_{\mathrm{B} 9-23}^{+} \mathrm{CD}^{+} \mathrm{T}$ cells, increased IL-4 and IL10 cytokines and reduced $\mathrm{GAD}^{+} \mathrm{CD}^{+} \mathrm{T}$ cell proliferation (85). This study magnifies the role of the gut mucosal immunity in the development of T1D. As such, an impaired thymus, the site for $\mathrm{T}$ cell selection and maturation including the IELs, accelerates autoimmune diabetes in mice. Remarkably, transfer of purified TCR $\gamma \delta^{+} \mathrm{CD} 8 \alpha \alpha^{+}$IELs from NOD mice prevented diabetes by reconstituting the small intestine IELs compartment of recipient mice that have undergone neonatal thymectomy (86). There is however, evidence to suggest a pathogenic role for $\mathrm{TCR} \gamma \delta^{+}$cells in T1D, as adoptive transfer of a specific subset $\left(\mathrm{CD} 27^{-} \mathrm{TCR} \gamma \delta^{+}\right)$of these cells into NOD.SCID recipients accelerated T1D development. Besides, knockdown of the TCR $\delta$ receptor in NOD mice offered robust T1D protection (7). As the studies above have shown, there is more than meets the eye when it comes to the role of TCR $\gamma \delta^{+}$cells in the story of T1D pathogenesis.

Our research group has focused on new insights studying the connectivity between the gut microbiota, mucosal immune system and diet for the prevention and cure of T1D. We were the first ones to elucidate that an altered gut microbiota and reduced production of SCFAs are signatures of T1D in NOD mice as it has been recently confirmed in individuals with T1D (21). We showed that exacerbated immune responses against islet antigens and increased gut leakiness were ameliorated by specifically augmenting the delivery of dietary acetate and butyrate. Therefore, we use a dietary intervention as an alternative therapeutic approach to halt immune-mediated beta-cell damage, promote a balanced and healthy gut microbiota, and abrogate the progression to clinical diabetes. We demonstrated that high SCFAs-yielding diets protected NOD mice from autoimmune diabetes (5). Acetate regulated autoreactive $\mathrm{CD}^{+} \mathrm{T}$ cells through changes in $\mathrm{B}$ cell differentiation and function. On the other hand, butyrate enhanced splenic and colonic Foxp $3^{+} \mathrm{T}_{\text {reg }}$ cell numbers through histone modification. Moreover, the diets high in acetate and butyrate significantly restored gut epithelial integrity by reducing circulating bacterial lipopolysaccharide (LPS) concentration, correlated an with increased expression of occludin. Recently we have shown, consistent with the previous results, that high butyrate-yielding diets increased the number of colonic TCR $\gamma \delta^{+}$ IELs associated with increased thymic IEL precursors (Y. Yap \& E. Mariño, unpublished data). Overall, our results demonstrated the astonishingly beneficial effects of high SCFA-yielding diets, by

\section{REFERENCES}

1. Flach M, Diefenbach A. Development of gut-associated lymphoid tissues. In: Mestecky J, Strober W, Russell MW, Kelsall BL, Cheroutre H, Lambrecht BN, editors. Mucosal Immunology, 4th Edn. Boston, MA: Academic Press (2015). p. 31-42. doi: 10.1016/B978-0-12-415847-4.00003-3 targeting both the gut microbiota and the immune system, thus offering a promising outcome on the prevention and treatment of autoimmune and inflammatory diseases.

Whilst supplementation of dietary SCFAs proved to be a safe and non-invasive therapy in a mouse model of T1D (5), one cannot help but wonder if using dietary supplementation together with current pharmaceutical approaches will favorably and greatly increase treatment efficacy. Indeed, therapies combining dietary treatment with immunotherapy are now starting to be tested in various disease models. For example, a very recent study testing the combination of a ketogenic diet and PI3K inhibitors, such as metformin and SGLT2, demonstrated significantly enhanced efficacy/toxicity ratios in various murine models of cancer (112). If these findings were successfully, translation into human clinical trials may revolutionize our current therapeutic strategies to eventually pair dietary or medicinal food supplementation with targeted immunotherapy for the treatment of many autoimmune and inflammatory diseases.

\section{CONCLUDING REMARKS}

Altogether, these studies provide validation that the impact of dietary metabolites within the gut has local as well as far-reaching anti-inflammatory effects on host health. Taken together, these findings accentuate the powerful impact the triage of intestinal immune health, the gut microbiota and dietary factors have in the pathogenesis of various autoimmune and inflammatory diseases such as T1D, infections and IBD. Much effort has been made in recent years to uncover the exact mechanisms behind their effects on health and disease. We are advancing on sophisticated methods such as genomics, transcriptomics, proteomics, metabolomics and nutrition that allow us to understand how this dynamic trio works together. While more studies in humans are required, dietary SCFAs have shown to be promising novel therapeutics. Dietary SCFAs therapy may be specifically tailored and designed, alone or in combination with potential immunotherapies, to prevent or cure diseases, where the future of medicine lies.

\section{AUTHOR CONTRIBUTIONS}

All authors listed have made a substantial, direct and intellectual contribution to the work, and approved it for publication.

\section{FUNDING}

This review is supported by the MBio Postgraduate Discovery Scholarship (awarded in 2015) from Monash University.
2. Kamada N, Seo S-U, Chen GY, Núñez G. Role of the gut microbiota in immunity and inflammatory disease. Nat Rev Immunol. (2013) 13:321. doi: $10.1038 /$ nri3430

3. Littman DR, Pamer EG. Role of the commensal microbiota in normal and pathogenic host immune responses. Cell Host Microbe (2011) 10:311-23. doi: 10.1016/j.chom.2011.10.004 
4. Maynard CL, Elson CO, Hatton RD, Weaver CT. Reciprocal interactions of the intestinal microbiota and immune system. Nature (2012) 489:231-41. doi: $10.1038 /$ nature 11551

5. Marino E, Richards JL, McLeod KH, Stanley D, Yap YA, Knight J, et al. Gut microbial metabolites limit the frequency of autoimmune $\mathrm{T}$ cells and protect against type 1 diabetes. Nat Immunol. (2017) 18:552-62. doi: 10.1038/ni.3713

6. Wen L, Ley RE, Volchkov PV, Stranges PB, Avanesyan L, Stonebraker AC, et al. Innate immunity and intestinal microbiota in the development of Type 1 diabetes. Nature (2008) 455(7216):1109-13. doi: 10.1038/nature07336

7. Markle JG, Mortin-Toth S, Wong AS, Geng L, Hayday A, Danska JS. gammadelta $\mathrm{T}$ cells are essential effectors of type 1 diabetes in the nonobese diabetic mouse model. J Immunol. (2013) 190:5392-401. doi: 10.4049/jimmunol.1203502

8. Mullaney JA, Stephens JE, Costello M-E, Fong C, Geeling BE, Gavin PG, et al. Type 1 diabetes susceptibility alleles are associated with distinct alterations in the gut microbiota. Microbiome (2018) 6:35. doi: 10.1186/s40168-018-0417-4

9. Markle JG, Frank DN, Mortin-Toth S, Robertson CE, Feazel LM, Rolle-Kampczyk U, et al. Sex differences in the gut microbiome drive hormone-dependent regulation of autoimmunity. Science (2013) 339:10848. doi: 10.1126/science. 1233521

10. Sun J, Furio L, Mecheri R, van der Does AM, Lundeberg E, Saveanu L, et al. Pancreatic beta-cells limit autoimmune diabetes via an immunoregulatory antimicrobial peptide expressed under the influence of the gut microbiota. Immunity (2015) 43:304-17. doi: 10.1016/j.immuni.2015.07.013

11. Neu J, Reverte CM, Mackey AD, Liboni K, Tuhacek-Tenace LM, Hatch M, et al. Changes in intestinal morphology and permeability in the biobreeding rat before the onset of type 1 diabetes. J Pediatr Gastroenterol Nutr. (2005) 40:589-95. doi: 10.1097/01.MPG.0000159636.19346.C1

12. Tai N, Peng J, Liu F, Gulden E, Hu Y, Zhang X, et al. Microbial antigen mimics activate diabetogenic CD8 T cells in NOD mice. J Exp Med. (2016) 213:2129-46. doi: 10.1084/jem.20160526

13. Kostic AD, Gevers D, Siljander $H$, Vatanen $T$, Hyotylainen $T$, Hamalainen AM, et al. The dynamics of the human infant gut microbiome in development and in progression toward type 1 diabetes. Cell Host Microbe (2015) 17:260-73. doi: 10.1016/j.chom.2015. 01.001

14. Giongo A, Gano KA, Crabb DB, Mukherjee N, Novelo LL, Casella G, et al. Toward defining the autoimmune microbiome for type 1 diabetes. ISME J. (2011) 5:82-91. doi: 10.1038/ismej.2010.92

15. Brown CT, Davis-Richardson AG, Giongo A, Gano KA, Crabb DB, Mukherjee $\mathrm{N}$, et al. Gut microbiome metagenomics analysis suggests a functional model for the development of autoimmunity for type 1 diabetes. PLoS ONE (2011) 6:e25792. doi: 10.1371/journal.pone.0025792

16. de Goffau MC, Luopajarvi K, Knip M, Ilonen J, Ruohtula T, Harkonen $\mathrm{T}$, et al. Fecal microbiota composition differs between children with beta-cell autoimmunity and those without. Diabetes (2013) 62:1238-44. doi: $10.2337 / \mathrm{db} 12-0526$

17. Bosi E, Molteni L, Radaelli MG, Folini L, Fermo I, Bazzigaluppi E, et al. Increased intestinal permeability precedes clinical onset of type 1 diabetes. Diabetologia (2006) 49:2824-7. doi: 10.1007/s00125-006-0465-3

18. Westerholm-Ormio M, Vaarala O, Pihkala P, Ilonen J, Savilahti E. Immunologic activity in the small intestinal mucosa of pediatric patients with type 1 diabetes. Diabetes (2003) 52:2287-95. doi: $10.2337 /$ diabetes.52.9.2287

19. Tiittanen M, Westerholm-Ormio M, Verkasalo M, Savilahti E, Vaarala O. Infiltration of forkhead box P3-expressing cells in small intestinal mucosa in coeliac disease but not in type 1 diabetes. Clin Exp Immunol. (2008) 152:498-507. doi: 10.1111/j.1365-2249.2008.03662.x

20. Marwaha AK, Crome SQ, Panagiotopoulos C, Berg KB, Qin H, Ouyang Q, et al. Cutting edge: Increased IL-17-secreting $\mathrm{T}$ cells in children with new-onset type 1 diabetes. J Immunol. (2010) 185:3814-8. doi: 10.4049/jimmunol.1001860

21. Vatanen T, Franzosa EA, Schwager R, Tripathi S, Arthur TD, Vehik K, et al. The human gut microbiome in early-onset type 1 diabetes from the TEDDY study. Nature (2018) 562:589-94. doi: 10.1038/s41586-0180620-2

22. Macia L, Tan J, Vieira AT, Leach K, Stanley D, Luong S, et al. Metabolitesensing receptors GPR43 and GPR109A facilitate dietary fibre-induced gut homeostasis through regulation of the inflammasome. Nat Commun. (2015) 6:6734. doi: 10.1038/ncomms7734

23. Singh N, Gurav A, Sivaprakasam S, Brady E, Padia R, Shi H, et al. Activation of Gpr109a, receptor for niacin and the commensal metabolite butyrate, suppresses colonic inflammation and carcinogenesis. Immunity (2014) 40:128-39. doi: 10.1016/j.immuni.2013.12.007

24. Frank DN, St. Amand AL, Feldman RA, Boedeker EC, Harpaz N, Pace NR. Molecular-phylogenetic characterization of microbial community imbalances in human inflammatory bowel diseases. Proc Natl Acad Sci USA (2007) 104:13780-5. doi: 10.1073/pnas.0706625104

25. Wang T, Cai G, Qiu Y, Fei N, Zhang M, Pang X, et al. Structural segregation of gut microbiota between colorectal cancer patients and healthy volunteers. ISME J. (2012) 6:320-9. doi: 10.1038/ismej.2011.109

26. Cervantes-Barragan L, Chai JN, Tianero MD, Di Luccia B, Ahern PP, Merriman J, et al. Lactobacillus reuteri induces gut intraepithelial CD4+CD8 $\alpha \alpha+\mathrm{T}$ cells. Science (2017) 357:806-10. doi: $10.1126 /$ science.aah5825

27. Das G, Augustine MM, Das J, Bottomly K, Ray P, Ray A. An important regulatory role for $\mathrm{CD} 4+\mathrm{CD} 8 \alpha \alpha \mathrm{T}$ cells in the intestinal epithelial layer in the prevention of inflammatory bowel disease. Proc Natl Acad Sci USA (2003) 100:5324-9. doi: 10.1073/pnas.0831037100

28. Van Kaer L, Olivares-Villagomez D. Development, homeostasis, and functions of intestinal intraepithelial lymphocytes. J Immunol. (2018) 200:2235-44. doi: 10.4049/jimmunol.1701704

29. Sujino T, London M, Hoytema van Konijnenburg DP, Rendon T, Buch T, Silva HM, et al. Tissue adaptation of regulatory and intraepithelial CD4(+) T cells controls gut inflammation. Science (2016) 352:1581-6. doi: $10.1126 /$ science.aaf3892

30. Simpson Stephen J, Holländer Georg A, Mizoguchi E, Allen D, Bhan Atul K, Wang B, et al. Expression of pro-inflammatory cytokines by TCR $\alpha \beta+\mathrm{T}$ and TCR $\gamma \delta+$ T cells in an experimental model of colitis. Eur J Immunol. (1997) 27:17-25. doi: 10.1002/eji.1830270104

31. Park SG, Mathur R, Long M, Hosh N, Hao L, Hayden MS, et al. T Regulatory cells maintain intestinal homeostasis by suppressing $\gamma \delta \mathrm{T}$ cells. Immunity (2010) 33:791-803. doi: 10.1016/j.immuni.2010.10.014

32. Lepage AC, Buzoni-Gatel D, Bout DT, Kasper LH. Gut-derived intraepithelial lymphocytes induce long term immunity against Toxoplasma gondii. $J$ Immunol. (1998) 161:4902-8.

33. Muller S, Buhler-Jungo M, Mueller C. Intestinal intraepithelial lymphocytes exert potent protective cytotoxic activity during an acute virus infection. $J$ Immunol. (2000) 164:1986-94. doi: 10.4049/jimmunol.164.4.1986

34. Imaoka A, Matsumoto S, Setoyama H, Okada Y, Umesaki Y. Proliferative recruitment of intestinal intraepithelial lymphocytes after microbial colonization of germ-free mice. Eur J Immunol. (1996) 26:945-8. doi: 10.1002/eji.1830260434

35. Regnault A, Levraud JP, Lim A, Six A, Moreau C, Cumano A, et al. The expansion and selection of $\mathrm{T}$ cell receptor alpha beta intestinal intraepithelial T cell clones. Eur J Immunol. (1996) 26:914-21. doi: 10.1002/eji.1830260429

36. Edelblum KL, Shen L, Weber CR, Marchiando AM, Clay BS, Wang Y, et al. Dynamic migration of gammadelta intraepithelial lymphocytes requires occludin. Proc Natl Acad Sci USA (2012) 109:7097-102. doi: 10.1073/pnas.1112519109

37. Edelblum KL, Singh G, Odenwald MA, Lingaraju A, El Bissati K, McLeod R, et al. gammadelta intraepithelial lymphocyte migration limits transepithelial pathogen invasion and systemic disease in mice. Gastroenterology (2015) 148:1417-26. doi: 10.1053/j.gastro.2015.02.053

38. Ismail AS, Severson KM, Vaishnava S, Behrendt CL, Yu X, Benjamin JL, et al. $\gamma \delta$ intraepithelial lymphocytes are essential mediators of host-microbial homeostasis at the intestinal mucosal surface. Proc Natl Acad Sci USA (2011) 108:8743-8. doi: 10.1073/pnas.1019574108

39. Dalton JE, Cruickshank SM, Egan CE, Mears R, Newton DJ, Andrew EM, et al. Intraepithelial $\gamma \delta+$ lymphocytes maintain the integrity of intestinal epithelial tight junctions in response to infection. Gastroenterology (2006) 131:818-29. doi: 10.1053/j.gastro.2006.06.003

40. Inagaki-Ohara K, Sakamoto Y, Dohi T, Smith AL. $\gamma \delta \mathrm{T}$ cells play a protective role during infection with Nippostrongylus brasiliensis by promoting goblet cell function in the small intestine. Immunology (2011) 134:448-58. doi: $10.1111 / j .1365-2567.2011 .03503 . x$ 
41. Ma LJ, Acero LF, Zal T, Schluns KS. Trans-presentation of IL-15 by intestinal epithelial cells drives development of CD8alphaalpha IELs. J Immunol. (2009) 183:1044-54. doi: 10.4049/jimmunol.0900420

42. Hu MD, Ethridge AD, Lipstein R, Kumar S, Wang Y, Jabri B, et al. Epithelial IL-15 is a critical regulator of $\gamma \delta$ intraepithelial lymphocyte motility within the intestinal mucosa. J Immunol. (2018) 201:747. doi: 10.4049/jimmunol.1701603

43. Hyun J, Romero L, Riveron R, Flores C, Kanagavelu S, Chung KD, et al. Human intestinal epithelial cells express interleukin-10 through Tolllike receptor 4-mediated epithelial-macrophage crosstalk. J Innate Immun. (2015) 7:87-101. doi: 10.1159/000365417

44. Marchiando AM, Graham WV, Turner JR. Epithelial barriers in homeostasis and disease. Annu Rev Pathol Mech Dis. (2010) 5:119-44. doi: 10.1146/annurev.pathol.4.110807.092135

45. Peterson LW, Artis D. Intestinal epithelial cells: regulators of barrier function and immune homeostasis. Nat Rev Immunol. (2014) 14:141. doi: $10.1038 /$ nri3608

46. Gallo RL, Hooper LV. Epithelial antimicrobial defence of the skin and intestine. Nat Rev Immunol. (2012) 12:503. doi: 10.1038/nri3228

47. Bevins CL, Salzman NH. Paneth cells, antimicrobial peptides and maintenance of intestinal homeostasis. Nat Rev Microbiol. (2011) 9:356-68. doi: $10.1038 /$ nrmicro2546

48. Mukherjee S, Zheng H, Derebe MG, Callenberg KM, Partch CL, Rollins D, et al. Antibacterial membrane attack by a pore-forming intestinal C-type lectin. Nature (2014) 505:103-7. doi: 10.1038/nature12729

49. Everard A, Geurts L, Caesar R, Van Hul M, Matamoros S, Duparc T, et al. Intestinal epithelial MyD88 is a sensor switching host metabolism towards obesity according to nutritional status. Nat Commun. (2014) 5:5648. doi: $10.1038 /$ ncomms6648

50. Ley RE, Backhed F, Turnbaugh P, Lozupone CA, Knight RD, Gordon JI. Obesity alters gut microbial ecology. Proc Natl Acad Sci USA (2005) 102:11070-5. doi: 10.1073/pnas.0504978102

51. Turnbaugh PJ, Ley RE, Mahowald MA, Magrini V, Mardis ER, Gordon JI. An obesity-associated gut microbiome with increased capacity for energy harvest. Nature (2006) 444:1027-31. doi: 10.1038/nature05414

52. Shulzhenko N, Morgun A, Hsiao W, Battle M, Yao M, Gavrilova O, et al. Crosstalk between B lymphocytes, microbiota and the intestinal epithelium governs immunity versus metabolism in the gut. Nat Med. (2011) 17:158593. doi: 10.1038/nm.2505

53. Mabbott NA, Donaldson DS, Ohno H, Williams IR, Mahajan A. Microfold (M) cells: important immunosurveillance posts in the intestinal epithelium. Mucosal Immunol. (2013) 6:666-77. doi: 10.1038/mi.2013.30

54. Mowat AM. Anatomical basis of tolerance and immunity to intestinal antigens. Nat Rev Immunol. (2003) 3:331. doi: 10.1038/nri1057

55. Rescigno M. Intestinal microbiota and its effects on the immune system. Cell Microbiol. (2014) 16:1004-13. doi: 10.1111/cmi.12301

56. Makki K, Deehan EC, Walter J, Bäckhed F. The impact of dietary fiber on gut microbiota in host health and disease. Cell Host Microbe (2018) 23:705-15. doi: 10.1016/j.chom.2018.05.012

57. Wrzosek L, Miquel S, Noordine M-L, Bouet S, Chevalier-Curt MJ, Robert V, et al. Bacteroides thetaiotaomicron and Faecalibacterium prausnitziiinfluence the production of mucus glycans and the development of goblet cells in the colonic epithelium of a gnotobiotic model rodent. BMC Biol. (2013) 11:61. doi: 10.1186/1741-7007-11-61

58. Desai MS, Seekatz AM, Koropatkin NM, Kamada N, Hickey CA, Wolter $\mathrm{M}$, et al. A dietary fiber-deprived gut microbiota degrades the colonic mucus barrier and enhances pathogen susceptibility. Cell (2016) 167: 1339-53.e21. doi: 10.1016/j.cell.2016.10.043

59. Bergstrom KSB, Kissoon-Singh V, Gibson DL, Ma C, Montero M, Sham HP, et al. Muc2 protects against lethal infectious colitis by disassociating pathogenic and commensal bacteria from the colonic mucosa. PLoS Pathog. (2010) 6:e1000902. doi: 10.1371/journal.ppat.1000902

60. Schroeder BO, Birchenough GMH, Stahlman M, Arike L, Johansson MEV, Hansson GC, et al. Bifidobacteria or fiber protects against diet-induced microbiota-mediated colonic mucus deterioration. Cell Host Microbe (2018) 23:27-40 e7. doi: 10.1016/j.chom.2017.11.004
61. Fukuda S, Toh H, Hase K, Oshima K, Nakanishi Y, Yoshimura K, et al. Bifidobacteria can protect from enteropathogenic infection through production of acetate. Nature (2011) 469:543-9. doi: 10.1038/nature09646

62. Zou J, Chassaing B, Singh V, Pellizzon M, Ricci M, Fythe MD, et al. Fiber-mediated nourishment of gut microbiota protects against diet-induced obesity by restoring IL-22-mediated colonic health. Cell Host Microbe (2018) 23:41-53.e4. doi: 10.1016/j.chom.2017.11.003

63. Cheroutre H, Lambolez F, Mucida D. The light and dark sides of intestinal intraepithelial lymphocytes. Nat Rev Immunol. (2011) 11:445. doi: $10.1038 /$ nri3007

64. Olivares-Villagomez D, Van Kaer L. Intestinal intraepithelial lymphocytes: sentinels of the mucosal barrier. Trends Immunol. (2017) 39, 264-75. doi: 10.1016/j.it.2017.11.003

65. Morrissey PJ, Charrier K, Horovitz DA, Fletcher FA, Watson JD. Analysis of the intra-epithelial lymphocyte compartment in SCID mice that received coisogenic CD4+ T cells: Evidence that mature post-thymic CD4+ T cells can be induced to express CD8 $\alpha$ in vivo. J Immunol. (1995) 154:2678-86.

66. Aranda R, Sydora BC, McAllister PL, Binder SW, Yang HY, Targan SR, et al. Analysis of intestinal lymphocytes in mouse colitis mediated by transfer of CD4+, CD45RBhigh T Cells to SCID recipients. J Immunol. (1997) 158:3464-73.

67. Jarry A, Cerf-bensussan N, Brousse N, Selz F, Guy-grand D. Subsets of $\mathrm{CD} 3+(\mathrm{T}$ cell receptor $\alpha / \beta$ or $\gamma / \delta)$ and CD3- lymphocytes isolated from normal human gut epithelium display phenotypical features different from their counterparts in peripheral blood. Eur J Immunol. (1990) 20:1097-103. doi: 10.1002/eji.1830200523

68. Mucida D, Husain MM, Muroi S, Van Wijk F, Shinnakasu R, Naoe Y, et al. Transcriptional reprogramming of mature CD4 + helper $\mathrm{T}$ cells generates distinct MHC class II-restricted cytotoxic T lymphocytes. Nat Immunol. (2013) 14:281-9. doi: 10.1038/ni.2523

69. Reis Bernardo S, Hoytema van Konijnenburg David P, Grivennikov Sergei I, Mucida D. Transcription factor T-bet regulates intraepithelial lymphocyte functional maturation. Immunity (2014) 41:244-56. doi: 10.1016/j.immuni.2014.06.017

70. Konkel JE, Maruyama T, Carpenter AC, Xiong Y, Zamarron BF, Hall BE, et al. Control of the development of CD8 $\alpha \alpha+$ intestinal intraepithelial lymphocytes by TGF- $\beta$. Nat Immunol. (2011) 12:312. doi: 10.1038/ ni.1997

71. Van Kaer L, Rabacal WAS, Scott Algood HM, Parekh VV, OlivaresVillagómez D. In vitro induction of regulatory CD4+CD $8 \alpha+$ $\mathrm{T}$ cells by TGF- $\beta$, IL-7 and IFN- $\gamma$. PLoS ONE (2013) 8:e67821. doi: 10.1371/journal.pone.0067821

72. Masopust D, Vezys V, Marzo AL, Lefrançois L. Preferential localization of effector memory cells in nonlymphoid tissue. Science (2001) 291:2413-7. doi: 10.1126/science. 1058867

73. Masopust D, Vezys V, Wherry EJ, Barber DL, Ahmed R. Cutting edge: Gut microenvironment promotes differentiation of a unique memory CD8 T cell population. J Immunol. (2006) 176:2079-83. doi: 10.4049/jimmunol.176.4.2079

74. Cheroutre H, Lambolez F. Doubting the TCR coreceptor function of CD8alphaalpha. Immunity (2008) 28:149-59. doi: 10.1016/j.immuni.2008.01.005

75. Chen B, Ni X, Sun R, Zeng B, Wei H, Tian Z, et al. Commensal bacteria-dependent $\mathrm{CD} 8 \alpha \beta(+) \mathrm{T}$ cells in the intestinal epithelium produce antimicrobial peptides. Front Immunol. (2018) 9:1065. doi: 10.3389/fimmu.2018.01065

76. Di Marco Barros R, Roberts NA, Dart RJ, Vantourout P, Jandke A, Nussbaumer $\mathrm{O}$, et al. Epithelia use butyrophilin-like molecules to shape organ-specific $\gamma \delta \mathrm{T}$ cell compartments. Cell (2016) 167:203-18.e17. doi: $10.1016 /$ j.cell.2016.08.030

77. Vantourout P, Hayday A. Six-of-the-best: Unique contributions of $\gamma \delta \mathrm{T}$ cells to immunology. Nat Rev Immunol. (2013) 13:88-100. doi: 10.1038/nri3384

78. Ismail AS, Behrendt CL, Hooper LV. Reciprocal interactions between commensal bacteria and $\gamma \delta$ intraepithelial lymphocytes during mucosal injury. J Immunol. (2009) 182:3047-54. doi: 10.4049/jimmunol. 0802705 
79. Hoytema van Konijnenburg DP, Reis BS, Pedicord VA, Farache J, Victora GD, Mucida D. Intestinal epithelial and intraepithelial $\mathrm{T}$ cell crosstalk mediates a dynamic response to infection. Cell (2017) 171:783-94 e13. doi: 10.1016/j.cell.2017.08.046

80. Yang H, Antony PA, Wildhaber BE, Teitelbaum DH. Intestinal intraepithelial lymphocyte gamma delta-T cell-derived keratinocyte growth factor modulates epithelial growth in the mouse. J Immunol. (2004) 172:4151-8. doi: 10.4049/jimmunol.172.7.4151

81. Chen Y, Chou K, Fuchs E, Havran WL, Boismenu R. Protection of the intestinal mucosa by intraepithelial $\gamma \delta$ T cells. Proc Natl Acad Sci USA (2002) 99:14338-43. doi: 10.1073/pnas.212290499

82. Tsuchiya T, Fukuda S, Hamada H, Nakamura A, Kohama Y, Ishikawa H, et al. Role of $\gamma \delta \mathrm{T}$ cells in the inflammatory response of experimental colitis mice. J Immunol. (2003) 171:5507-13. doi: 10.4049/jimmunol.171.10.5507

83. Canesso MCC, Lemos L, Neves TC, Marim FM, Castro TBR, Veloso É, et al. The cytosolic sensor STING is required for intestinal homeostasis and control of inflammation. Mucosal Immunol. (2018) 11:820-34. doi: $10.1038 / \mathrm{mi} .2017 .88$

84. Benakis C, Brea D, Caballero S, Faraco G, Moore J, Murphy M, et al. Commensal microbiota affects ischemic stroke outcome by regulating intestinal gammadelta $\mathrm{T}$ cells. Nat Med. (2016) 22:516-23. doi: $10.1038 / \mathrm{nm} .4068$

85. Harrison LC, Dempsey-Collier M, Kramer DR, Takahashi K. Aerosol insulin induces regulatory CD8 gamma delta $\mathrm{T}$ cells that prevent murine insulin-dependent diabetes. J Exp Med. (1996) 184:2167-74. doi: 10.1084/jem.184.6.2167

86. Locke NR, Stankovic S, Funda DP, Harrison LC. TCR gamma delta intraepithelial lymphocytes are required for self-tolerance. J Immunol. (2006) 176:6553-9. doi: 10.4049/jimmunol.176.11.6553

87. Han G, Wang R, Chen G, Wang J, Xu R, Wang L, et al. Interleukin17-producing gammadelta $+\mathrm{T}$ cells protect NOD mice from type 1 diabetes through a mechanism involving transforming growth factor-beta. Immunology (2010) 129:197-206. doi: 10.1111/j.1365-2567.2009.03166.x

88. Rothschild D, Weissbrod O, Barkan E, Kurilshikov A, Korem T, Zeevi D, et al. Environment dominates over host genetics in shaping human gut microbiota. Nature (2018) 555:210. doi: 10.1038/nature25973

89. Thorburn AN, McKenzie CI, Shen S, Stanley D, Macia L, Mason LJ, et al. Evidence that asthma is a developmental origin disease influenced by maternal diet and bacterial metabolites. Nat Commun. (2015) 6:7320. doi: $10.1038 /$ ncomms 8320

90. Tan J, McKenzie C, Vuillermin PJ, Goverse G, Vinuesa CG, Mebius RE, et al. Dietary fiber and bacterial SCFA enhance oral tolerance and protect against food allergy through diverse cellular pathways. Cell Rep. (2016) 15:2809-24. doi: 10.1016/j.celrep.2016.05.047

91. Chassaing B, Koren O, Goodrich JK, Poole AC, Srinivasan S, Ley RE, et al. Dietary emulsifiers impact the mouse gut microbiota promoting colitis and metabolic syndrome. Nature (2015) 519:92-6. doi: 10.1038/nature14232

92. Thorburn AN, Macia L, Mackay CR. Diet, metabolites, and "westernlifestyle” inflammatory diseases. Immunity (2014) 40:833-42. doi: 10.1016/j.immuni.2014.05.014

93. Maslowski KM, Mackay CR. Diet, gut microbiota and immune responses. Nat Immunol. (2011) 12:5-9. doi: 10.1038/ni0111-5

94. Richards JL, Yap YA, McLeod KH, Mackay CR, Marino E. Dietary metabolites and the gut microbiota: an alternative approach to control inflammatory and autoimmune diseases. Clin Trans Immunol. (2016) 5:e82. doi: 10.1038/cti.2016.29

95. De Filippo C, Di Paola M, Ramazzotti M, Albanese D, Pieraccini G, Banci E, et al. Diet, environments, and gut microbiota. A preliminary investigation in children living in rural and urban Burkina Faso and Italy. Front Microbiol. (2017) 8:1979. doi: 10.3389/fmicb.2017.01979

96. De Filippo C, Cavalieri D, Di Paola M, Ramazzotti M, Poullet JB, Massart S, et al. Impact of diet in shaping gut microbiota revealed by a comparative study in children from Europe and rural Africa. Proc Natl Acad Sci USA (2010) 107:14691-6. doi: 10.1073/pnas.1005963107

97. Arpaia N, Campbell C, Fan X, Dikiy S, van der Veeken J, deRoos P, et al. Metabolites produced by commensal bacteria promote peripheral regulatory T-cell generation. Nature (2013) 504:451-5. doi: 10.1038/nature12726

98. Kaisar MMM, Pelgrom LR, van der Ham AJ, Yazdanbakhsh M, Everts B. Butyrate conditions human dendritic cells to prime type 1 regulatory T cells via both histone deacetylase inhibition and G protein-coupled receptor 109A signaling. Front Immunol. (2017) 8:1429. doi: 10.3389/fimmu.2017.01429

99. Kim MH, Kang SG, Park JH, Yanagisawa M, Kim CH. Short-chain fatty acids activate GPR41 and GPR43 on intestinal epithelial cells to promote inflammatory responses in mice. Gastroenterology (2013) 145:396-406.e1-10. doi: 10.1053/j.gastro.2013.04.056

100. Smith PM, Howitt MR, Panikov N, Michaud M, Gallini CA, Bohlooly YM, et al. The microbial metabolites, short-chain fatty acids, regulate colonic Treg cell homeostasis. Science (2013) 341:569-73. doi: 10.1126/science.1241165

101. Fellows R, Denizot J, Stellato C, Cuomo A, Jain P, Stoyanova E, et al. Microbiota derived short chain fatty acids promote histone crotonylation in the colon through histone deacetylases. Nat Commun. (2018) 9:105. doi: 10.1038/s41467-017-02651-5

102. Trompette A, Gollwitzer ES, Yadava K, Sichelstiel AK, Sprenger N, NgomBru C, et al. Gut microbiota metabolism of dietary fiber influences allergic airway disease and hematopoiesis. Nat Med. (2014) 20:159-66. doi: $10.1038 / \mathrm{nm} .3444$

103. Atkinson MA. The pathogenesis and natural history of type 1 diabetes. Cold Spring Harb Perspect Med. (2012) 2:a007641. doi: 10.1101/cshperspect.a007641

104. Vaarala O, Atkinson MA, Neu J. The "perfect storm" for type 1 diabetes: the complex interplay between intestinal microbiota, gut permeability, and mucosal immunity. Diabetes (2008) 57:2555-62. doi: 10.2337/db08-0331

105. Vaarala $O$. The gut as a regulator of early inflammation in type 1 diabetes. Curr Opin Endocrinol Diabetes Obes. (2011) 18:241-7. doi: 10.1097/MED.0b013e3283488218

106. Tuomilehto J. The emerging global epidemic of type 1 diabetes. Curr Diab Rep. (2013) 13:795-804. doi: 10.1007/s11892-013-0433-5

107. Maahs DM, West NA, Lawrence JM, Mayer-Davis EJ. Epidemiology of type 1 diabetes. Endocrinol Metab Clin North Am. (2010) 39:481-97. doi: 10.1016/j.ecl.2010.05.011

108. Rewers M, Ludvigsson J. Environmental risk factors for type 1 diabetes. Lancet (2016) 387:2340-8. doi: 10.1016/S0140-6736(16)30507-4

109. Boursi B, Mamtani R, Haynes K, Yang YX. The effect of past antibiotic exposure on diabetes risk. Eur J Endocrinol. (2015) 172:639-48. doi: 10.1530/EJE-14-1163

110. Belkaid Y, Hand TW. Role of the microbiota in immunity and inflammation. Cell (2014) 157:121-41. doi: 10.1016/j.cell.2014.03.011

111. Lee AS, Gibson DL, Zhang Y, Sham HP, Vallance BA, Dutz JP. Gut barrier disruption by an enteric bacterial pathogen accelerates insulitis in NOD mice. Diabetologia (2010) 53:741-8. doi: 10.1007/s00125-009-1626-y

112. Hopkins BD, Pauli C, Du X, Wang DG, Li X, Wu D, et al. Suppression of insulin feedback enhances the efficacy of PI3K inhibitors. Nature (2018) 560:499-503. doi: 10.1038/s41586-018-0343-4

Conflict of Interest Statement: The authors declare that the research was conducted in the absence of any commercial or financial relationships that could be construed as a potential conflict of interest.

Copyright (c) 2018 Yap and Mariño. This is an open-access article distributed under the terms of the Creative Commons Attribution License (CC BY). The use, distribution or reproduction in other forums is permitted, provided the original author(s) and the copyright owner(s) are credited and that the original publication in this journal is cited, in accordance with accepted academic practice. No use, distribution or reproduction is permitted which does not comply with these terms. 